\title{
The Effect of Vocabulary Cluster on Iranian Intermediate EFL Learners' Vocabulary Achievement
}

\author{
Masoud KhaliliSabet \\ English Department, Guilan University \\ PO box 41635-3988 Rasht,Iran \\ E-mail:Sabetma2002@yahoo.com \\ Mitra Mousazadeh Sayyadmahaleh (Corresponding author) \\ English Department, Guilan University \\ Rasht,Iran \\ E-mail:Mitra.Mousazadeh@yahoo.com
}

Received: 12-07-2014

doi:10.7575/aiac.ijalel.v.4n.1p.209
Accepted: 07-09-2014

Published: 01-01-2015

\begin{abstract}
This study intended to inspect the possible effects of vocabulary cluster on Iranian Intermediate EFL learners' vocabulary achievement. It was based on the comparison between semantically and thematically -related sets to find out which type of vocabulary learning cluster was more effective on learners vocabulary learning. Sixty intermediate EFL learners were selected based on their performance on OPT test and then were randomly assigned into three groups each containing 20 subjects (one control and two experimental groups). Quasi-experimental design was used in which Pre-test and post-test were administered to collect data. The researcher employed Nations word level test as the pre-test to examine the participants' initial knowledge of common words. The experimental group (A) worked on thematic clustering, while experimental group (B) received instruction on semantic clustering and the control group received placebo. Next, all participants took part in vocabulary size test to evaluate the vocabulary achievement of the participants. The scores obtained from pre-test and post-test were analyzed through running paired sample t-test, and one-way ANOVA. The results indicated that the experimental group (B) which received semantically related sets outperformed the control group \& the experimental group (A) which received thematically related sets. This may have significant implications for language instructors, syllabus designers, and learners to make more advancement in vocabulary learning process through employing vocabulary cluster.
\end{abstract}

Keywords: Semantic clustering, Thematic clustering, Semantic field

\section{Introduction}

Teaching and learning vocabulary is one of the main features in the process of learning and teaching a second or foreign language. Since a word with all the varied definitions and notions it contains is determined the center of the language. According to Al-Jarf , 2007 many instructional plans have been formulated and employed by Second/Foreign language teachers in order to expand general and academic vocabulary of students. Decarrico (2001) believes that strategies should help learners to become aware of the meaning of a new word and consolidate the word in memory after it has been learned. Instructing strategies in an explicit manner has been identified to be the most significant and influential factor in the performance of foreign language learners. Luke (2006) describes explicit strategy teaching by three main elements including explicit practice, strategy cues, and elaboration. According to Tagashiro, Kid \& Hoshino (2010), in foreign language classrooms one of the most admired approaches for introducing new vocabulary items is presenting them in thematically or semantically-related sets. As stated by Tinkham (1997), units clustered thematically can be "subconsciously arranged in a manner conforming to their involvement within certain frames or schemata, concepts which splits a speaker's background knowledge" (p.141).

A vocabulary cluster is an approach to learning words by associating them into different related groups. Erten and Tekin (2008), reflecting on their own findings, assert that presenting new words new words in semantic sets, rather than in semantically unrelated word groups, can interfere with learning. Their study showed that, contrary to frequent practice in many course books, presenting new vocabulary that belongs to the same semantic set together may cause interference due to cross-association and may even impede vocabulary learning (p.407). This is an effective method because it is easier to remember words that have a conceptual relationship with each other than to remember a random list. According to Tinkham (1997) and Waring(1997),here is a difference between the presentation of new words in semantic sets and presenting them in thematic sets. Tinkham and Waring advocate a thematic rather than a semantic planning of new lexical items. The words in a thematic group are speakers .The new words to be learned were in pairs, English words, and artificial word in related and unrelated semantic clusters. According to Bruton, Lopez, \& Mesa, 
2011) one significant argument over the years has been the distinction between incidental \& intentional vocabulary learning. The students are given lists of words or pictures that are most related to particular topic or situation (Bolger\& Zapata, 2011).

\section{Statement of the problem}

Vocabulary is an important element in learning language that often seems to be a source of problem for many language learners. Fu (2009) believed that words are the only instrument in expressing something; therefore, difficulty in vocabulary learning and recall lead to major problems in language use. Learning vocabulary is of great significance in learning a language. If foreign language learners have sufficient vocabulary domain, they will have considerable proficiency to understand what they hear\& read and thus they will be able to produce better language when they are speaking or writing. Providing necessary information for language learners to develop reliable vocabularies is necessary to their success at school and further studies. The most important factor in a successful vocabulary- building program is desire to learn and thus helping EFL learners to have strong desire to learn vocabulary items is of great importance for their success in language learning. Finding an effective method for vocabulary instruction has considerable significance and value and lexical knowledge is one of the essential factors in comprehending a text or oral speech. It appears that foreign and second language syllabus designers and textbook authors accept that the presentation of semantically \& syntactically related lexical items facilities vocabulary learning. The purpose of the present study is to examine the effects of two types of clustering on learning English vocabulary among Iranian EFL learners. The two concepts are employed to differentiate between two different methods of organizing lexical items including semantic clustering and thematic clustering. Semantic clustering is based on grouping words that share various semantic and syntactic characteristic on the other hand; thematic clustering is based on the psychological associations between clustered words and a shared thematic concept.

\section{Purpose of the study}

According to the problem stated above, the purposes of this study are to compare the effects of semantic and thematic clustering on learning English vocabulary, and to examine whether vocabulary clustering has any effect on Iranian intermediate EFL learner's vocabulary achievement.

\section{Research questions and hypotheses}

To fulfill the purpose of this study and to examine whether vocabulary clustering has any effect on Iranian intermediate EFL learner's vocabulary achievement \& the effect of semantic and thematic clustering on learning English vocabulary, the following research questions will be addressed.

Q1: Does teaching English vocabulary through focusing on the concept of semantic clustering affect Iranian intermediate EFL learners' vocabulary achievement?

Q2: Does teaching English vocabulary through focusing on the concept of thematic clustering affect Iranian intermediate EFL learners' vocabulary achievement?

Regarding the aforementioned research questions, the following hypotheses have been formulated:

HO1: Teaching English vocabulary through focusing on the concept of semantic clustering does not affect Iranian intermediate EFL learners' vocabulary achievement.

HO2: Teaching English vocabulary through focusing on the concept of thematic clustering does not affect Iranian intermediate EFL learners' vocabulary achievement.

\section{Methodology}

\subsection{Participants}

The participants of the study consisted of 60 female EFL students who were studying English in ZabanGostar Institute in Bandar Anzali. They were selected from among 131 female students with respect to their proficiency level that was considered as intermediate. Sample selection was based on OPT test direction ( Oxford Solution, 2005) which stated that the students who had +31 correct answers in grammar and vocabulary part and +8 correct answers in reading part were considered to be at intermediate level of language proficiency. Their age ranged from 21 to 32 .

\subsection{Instruments and Materials}

In this study, the following instruments were employed:

1. The Standardized Oxford Placement Test (OPT Solutions test, Oxford University Press): It was administered for selecting homogeneous samples.

2. Nations Word Level Test: It was administered to assess the vocabulary proficiency of the participants at the beginning of the study before introducing the specific treatment on vocabulary clustering.NWL examined the EFL learners' basic knowledge of common words. It consisted of 140 multiple-choice tests.

3. Vocabulary Size Test (version A):it was used to evaluate the vocabulary achievement of the participants of the three groups at the end of the study. It consisted of 100 multiple-choice tests.

\subsection{Procedure}

With regard to the nature of the study and the research questions, this study first, to select the main sample, the standardized Oxford Placement Test (OPT) was administered to 131 EFL students. The participants took the structure, vocabulary and reading comprehension sections of the test with a maximum possible score of 60 points. Based on OPT 
test direction 60 intermediate students whose score was 31+ in grammar and vocabulary and $8+$ in reading section were selected as the main sample for the present study. In the next step Nations Word Level Test, which was used to measure the vocabulary proficiency by assessing the EFL learners' basic knowledge of common words. Nations Word Level Test was administered to the three groups as pretest.

In the treatment phase of the study, the control group practiced the same target vocabulary of the experimental groups through a traditional method of teaching, without employing any specific vocabulary strategy in which the words were introduced out of context, without any thematic or semantic relationship to each other. For the two experimental groups, new intermediate words in appropriate contexts were adopted from a book titled "Intermediate Vocabulary" by Thomas (1986). It is a standard book in which some intermediate words has been presented in a context or followed by some relevant contexts. Ten passages were selected. Some modifications were made to the original passages of the book in terms of passage length but not in sentence structures or content. The passages for both experimental groups were the same. In each session, one passage was given to the students in experimental group. In semantic experimental group, the selected related words were taught through semantic clustering techniques. Each session the participants were presented 15 vocabularies for 10 sessions. On the other hand, in thematic clustering group, the teacher introduced the topic of the unit by drawing the concept map on the board and asked the students to think of words that might be related to the topic.

\subsection{Data Analysis}

In order to analyze the collected data, the participants' performances on pre and post-test were scored and subjected to the statistical analyses using SPSS 20. One Way ANOVA was conducted to the results of the pre- vocabulary test to examine the possible differences among the three groups in terms of their initial vocabulary proficiency at the beginning of the study before introducing the specific treatment of vocabulary clustering to the experimental groups and placebo to the control group. In fact, One Way ANOVA was run to examine the null hypotheses and investigated whether there was a significant difference among the three groups in terms of their vocabulary achievement or not.

\section{Results}

To establish that the subjects were more or less at almost identical level in terms of their lexical knowledge at the beginning of the study, a pretest was administered to the three groups. The main objective of directing the pretest was to determine a baseline from which the participants' presentation on the post-test could be assessed. To survey the fairness of variance assumption for the pretest, One Way ANOVA was run to the results of the pre-test.

Prior to fulfilling the analysis, the main supposition of One Way ANOVA specifically, normality of the distributions was evaluated through running Leven statistics. The results of Levene statistic revealed that the group variances were similar in vocabulary pre- test (P pre- test $(.115) \geq .05$. The Levene statistic confirmed the hypothesis that the group variances were the same (see also the following graph).

Table 1. One-way ANOVA for the pretest scores

\begin{tabular}{lrrrrr}
\hline & Sum of Squares & df & Mean Square & F & Sig. \\
\hline Between Groups & 8.233 & 2 & 4.117 & 1.358 & .265 \\
\hline Within Groups & 172.750 & 57 & 3.031 & & \\
\hline Total & 180.983 & 59 & & & \\
\hline
\end{tabular}

The significance value of the $\mathrm{F}$ test in the ANOVA table was greater than $(0.05)$ for the pretest. Thus, the Nonsignificant $\mathrm{F}$ test indicated that the population means were equal at the beginning of the study.it means that average assessment scores of vocabulary were equal across the three groups at the beginning of the study. The following figure illustrates that the three groups were homogenous in terms of their performance on vocabulary pre-test.

To answer the research questions, the One-Way ANOVA procedure produced a one-way analysis of variance for the quantitative dependent variable to be specific post vocabulary achievement by the single factor or independent variable (types of vocabulary cluster). Analysis of variance was used to test the hypothesis that the means of the three groups were equal on vocabulary post- test.

Table 2. Descriptive statistics for the posttest scores

\begin{tabular}{|c|c|c|c|c|c|c|c|c|}
\hline & \multirow[t]{2}{*}{$\mathrm{N}$} & \multirow[t]{2}{*}{ Mean } & \multirow[t]{2}{*}{$\begin{array}{c}\text { Std. } \\
\text { Deviation }\end{array}$} & \multirow[t]{2}{*}{$\begin{array}{l}\text { Std. } \\
\text { Error }\end{array}$} & \multicolumn{2}{|c|}{$\begin{array}{l}95 \% \text { Confidence } \\
\text { Interval for Mean }\end{array}$} & \multirow[t]{2}{*}{ Minimum } & \multirow[t]{2}{*}{ Maximum } \\
\hline & & & & & $\begin{array}{l}\text { Lower } \\
\text { Bound }\end{array}$ & $\begin{array}{l}\text { Upper } \\
\text { Bound }\end{array}$ & & \\
\hline control group & 20 & 14.85 & 2.0844 & .466 & 13.874 & 15.825 & 11.00 & 19.00 \\
\hline $\begin{array}{l}\text { experimental } \\
\text { group A } \\
\text { (thematic) }\end{array}$ & 20 & 17.30 & 1.4903 & .333 & 16.602 & 17.997 & 15.00 & 20.00 \\
\hline $\begin{array}{l}\text { experimental } \\
\text { group B } \\
\text { (semantic) }\end{array}$ & 20 & 17.75 & 1.6181 & .361 & 16.992 & 18.507 & 14.00 & 20.00 \\
\hline
\end{tabular}




$\begin{array}{lllllllll}\text { Total } & 60 & 16.63 & 2.1468 & .277 & 16.078 & 17.187 & 11.00 & 20.00\end{array}$

The results of the post-test showed that the Mean of the (control group) $=14.85$, Mean (experimental A- thematicgroup $)=17.30$, and Mean (experimental B- semantic- group) $=17.75$, differed statistically. The significance value of the $F$ test in the ANOVA table was less than (.05). Thus, the hypothesis that average assessment scores of the vocabulary test (post-test) were equal across the three groups was rejected (F 2, 57=15.91, Sig. $=.000 \leq .05)$.

Table 3. ANOVA for the Results of the Vocabulary Test (Post-Test)

\begin{tabular}{|c|c|c|c|c|c|}
\hline \multicolumn{6}{|c|}{ ANOVA } \\
\hline posttest & & & & & \\
\hline & Sum of Squares & df & Mean Square & $\mathrm{F}$ & Sig. \\
\hline Between Groups & 97.433 & 2 & 48.717 & 15.913 & .000 \\
\hline Within Groups & 174.500 & 57 & 3.061 & & \\
\hline Total & 271.933 & 59 & & & \\
\hline
\end{tabular}

The following figure illustrates mean plot for the results of the vocabulary posttest.

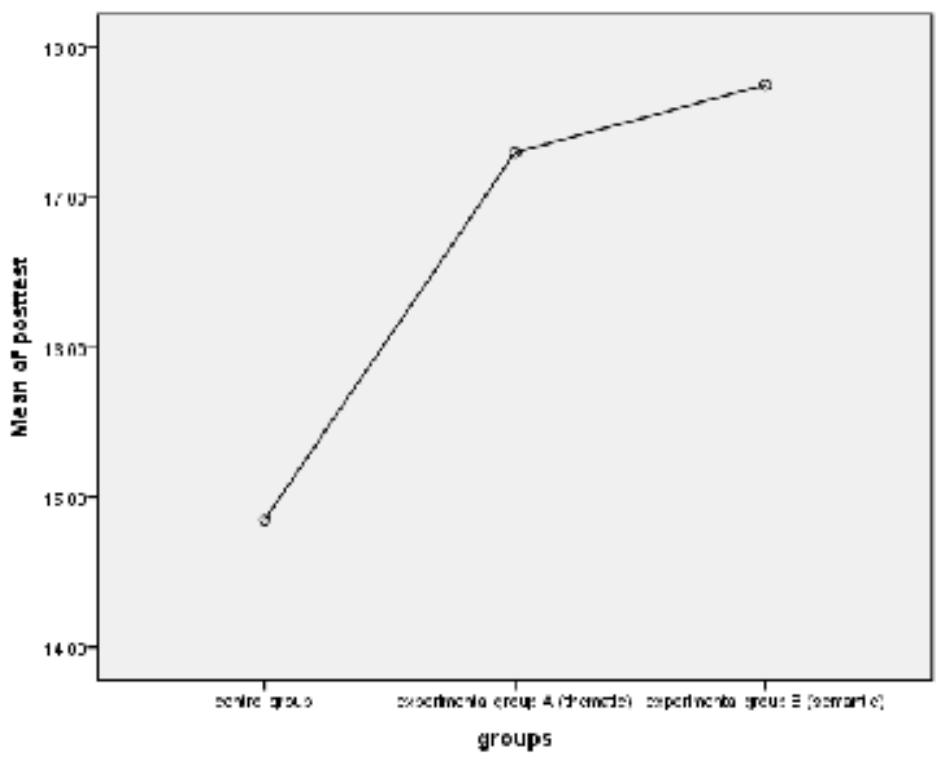

Figure1. Mean Plot for the Results of the vocabulary post Test

In general, $F$ statistics established that there was statistically a significant difference between the three groups' means, and means plots showed the location of these differences. Participants of the experimental group B (semantic clustering) outperformed their counterparts namely control group and experimental group (A). After it was revealed that the groups differed in some way, post- hoc test disclosed more about the structure of the differences. Before running the analysis of variance, the means and standard errors were graphed.

Table 4. Multiple Comparisons for the results of the posttest

Dependent Variable: posttest

Scheffe

(I) groups

Mean Difference

Std.

(I-J)

Error

Sig.

95\% Confidence Interval

Lower Upper

control group

experimental group

$-2.45000^{*}$

Bound

Bound

\begin{tabular}{|c|c|c|c|c|c|c|}
\hline & A (thematic) & & & & & \\
\hline & $\begin{array}{l}\text { experimental group } \\
\text { B (semantic) }\end{array}$ & $-2.90000^{*}$ & .55330 & .000 & -4.2907 & -1.5093 \\
\hline \multirow{2}{*}{$\begin{array}{l}\text { experimental } \\
\text { group A } \\
\text { (thematic) }\end{array}$} & control group & $2.45000^{*}$ & .55330 & .000 & 1.0593 & 3.8407 \\
\hline & $\begin{array}{l}\text { experimental group } \\
\text { B (semantic) }\end{array}$ & -.45000 & .55330 & .720 & -1.8407 & .9407 \\
\hline \multirow{2}{*}{$\begin{array}{l}\text { experimental } \\
\text { group B } \\
\text { (semantic) }\end{array}$} & control group & $2.90000^{*}$ & .55330 & .000 & 1.5093 & 4.2907 \\
\hline & $\begin{array}{l}\text { experimental group } \\
\text { A (thematic) }\end{array}$ & .45000 & .55330 & .720 & -.9407 & 1.8407 \\
\hline
\end{tabular}

*. The mean difference is significant at the 0.05 level. 
The following figure illustrates the performance of the three groups in posttest.

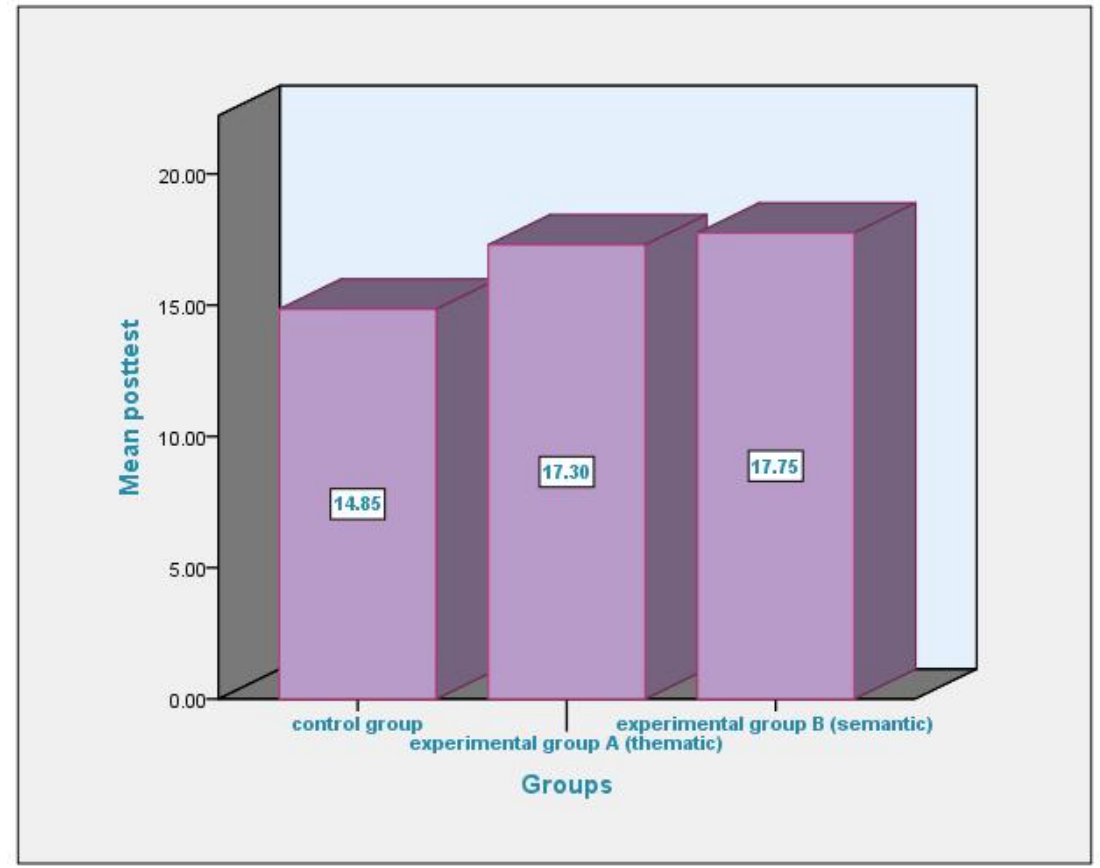

Figure 2. The Three Groups' Performances on Vocabulary test (Post-Test)

The highest mean difference was found between experimental $(B)$ group and control group mean difference $=(2.90)$. On the other hand, the lowest mean difference was reported for experimental (B) group and experimental (A) group (mean difference $=.45)$.

As it is shown in above tables, experimental group (B) outweighed the other two groups in terms of their vocabulary achievement (mean semantic group $=17.75 ; \mathrm{SD}=1.61$ ). In the second place, experimental (A) group performed better than the control group (mean thematic group $=17.30 ; \mathrm{SD}=1.49$ ). Finally, the control group's performance was lower than the other two groups (mean control group $=14.85 ; \mathrm{SD}=2.08$ ).

In order to investigate students' development within groups, three paired t-tests were also run.All the three groups had progressed in the post-test. Based on the results of paired T-test, this progress was statistically significant just for the experimental groups $(\mathrm{A})$ and $(\mathrm{B})$ groups $(\mathrm{P} \leq 0.05)$.

In other words, all the three groups made a substantially progress in the post- vocabulary test. Nevertheless, this progress was not statistically significant for the control group $(\mathrm{P} \geq 0.05)$.

These results also rejected the null hypotheses that semantic clustering of English vocabulary does not affect Iranian intermediate EFL learners' vocabulary achievement. Moreover, the findings rejected that thematic clustering of English vocabulary does not affect Iranian intermediate EFL learners' vocabulary achievement.

\section{Discussion}

The aim of the present study was to find out whether semantic and thematic vocabulary clustering could affect the vocabulary learning ability of EFL intermediate learners. This study tried to answer two research questions as which of the above mentioned clustering methods could play a role in vocabulary learning of the participants of Iranian intermediate EFL students who were selected based on their performance on OPT test. Finally, in order to investigate students' development within groups, three paired t-tests were also run, which showed all the three groups had progressed in the post-test. Based on the results of paired T-test, this progress was statistically significant just for the experimental groups (A) and (B) groups $(\mathrm{P} \leq 0.05)$. The results of the data analysis rejected both null hypotheses of the study and revealed that the methods of semantic and thematic vocabulary clustering affected the vocabulary achievement of the intermediate participants of this study. It can be concluded that both semantic and thematic vocabulary learning can have a facilitative role in the vocabulary achievement among the participants of the present study. It showed a significant gain in vocabulary using the thematic and semantic clustering method which is not a common method of vocabulary teaching especially in EFL contexts where often the teachers share a common language with learners. It should be first mentioned that there are some studies which deny the usefulness of this method of word organization on the vocabulary learning like those conducted by Finkbeiner and Nicol (2003) who summarized that "overall... presenting semantically grouped L2 words to learners has a deleterious effect on learning" (p. 376). Erten and Tekin (2008) in a study showed that test completion time for the semantically-related set was longer than in the semantically unrelated test, and also the results of vocabulary learning showed that semantically related clustering sets were harder to learn than the set of unrelated vocabulary. The findings of the present study, however, are compatible 
with the findings of some studies which had been reviewed in the review of literature in chapter two. Hashemi and Gowdasiaei (2005) showed that semantically-related presentation of vocabulary helps to facilitate learning rather than presenting unrelated sets of words. Gairns and Redman (1986) maintained that semantic clusters assist learners to apprehend the semantic divisions; to notice where definitions overlap and grasp the restriction of use of a concept'(p.32). They also believe that semantic clusters form building blocks and can be expanded as students' progress. It also provides a clear context for practice.

Likewise, Nation (2000) concludes that different writers provide justification for this clustering due to many reasons. He mentioned that retrieving vocabulary is easier when they are related. He also said that it is like the ways we save information in our brain. It helps learners understand how knowledge is organized. The result of the present research and the ones reviewed in the literature can have suggestions and generalizations for the educators, students, and text book writers. The effective use of semantic and thematic clustering in vocabulary learning and teaching can be facilitative in the vocabulary learning process. Like the similar results which had been reached in studies of HippnerPage (2002), Tinkham (1994), Gairns and Redman(1986),Seal (1991),Al-Jabri (2005) and many others, ), it can be suggested that there is strong possibility that learners can benefit from word semantic and thematic clustering and the vocabulary achievement in the groups of participants. Pedagogically, to teach vocabulary it is important that teachers and researchers find effective ways to help the language learners acquire vocabulary easier. Therefore, language practitioners need to find new ways and introduce them to their learners. Based on the results and findings of the present study organizing vocabulary is a facilitative method to achieve it more successfully. In this study, both semantic and thematic clustering proved to be effective for the learners at intermediate level. Therefore, using these methods can increase the learners' ability to acquire and learn. For the goal of language learning, it is a good idea that English dictionaries be devised by experts based on vocabulary categorization.

\section{Conclusion}

Most researchers came to the same conclusion that if they present words that share a common scheme existing in the mind (thematic clustering) they are easier to learn and remember. Researchers have explored the possibility that grouping words in a manner other than the traditional list of nouns, all fitting under a common theme, might be more beneficial for students. Hippner-Page (2002) showed both word groupings were beneficial, suggesting teachers might consider using both semantic and thematic groupings to help L2 elementary students learn new vocabulary words. This research can be expanded in its scope by investigating other factors which can play a role in the vocabulary achievement like proficiency levels, age factor, and different strategies of delivering in order to have a clear picture of how lexicons are processed by ESL/EFL learners. Some studies like Al-Jabri (2005) showed that proficiency levels and age variations can lead to different results.

\section{References}

Al-Jabri, S. (2005).The effects of semantic and thematic clustering on learning English vocabulary by Saudi

students. Retrieved May 7, 2011, from http://dspace.iup.edu/handle/2069/52.

Al-Jarf, R. (2007).Teaching vocabulary to EFL College students online. Retrieved March 22, 2010, from http://callej.org/journal/8-2/al-jarf.htmlChepyshko, R., \& Truscott, J. (2009). Semantic category effects in L2 vocabulary learning: A MOGULperspective (Master's thesis). Retrieved May 7,2011, from www.hss.nthu.edu.tw/ fl/thesis/tesol/945209.pdf .

Bolger,.\&Zapata,G.(2011).Semantic categories. Language learning journals,61(1),614-646.

Bruton,A.,Lopez,M.G.,\&Mesa,R.E.(2011).Incidental L2 vocabulary learning :an Impracticable Term? TESOL Quarterly,45, 759-768.

Decarrico, J.S. (2001). Vocabulary learning and teaching. In M. Celce-Murcia (Ed.), Teaching English as a second or foreign language ( $3 \mathrm{rd}$ ed.). Boston, MA: Heinle \& Heinle.

Erten,I.H.\&Tekin,M.(2008)"Effects of vocabulary Acquisition of presenting new words in semantic sets versus semantically unrelated sets". System,36(3), 407-22.

$\mathrm{Fu}$, J. (2009). A study of learning styles, teaching styles and vocabulary teaching strategies in Chinese primary school. Kristianstad University College: Sweden.

Finkbeiner,M.,\&Nicole,J.L.(2003).Semantic category effects in L2 word learning.Applied psycholinguistics 24(3),369383.

Graves,M.(2006).The vocabulary book: learning and instruction. New York: Teacher college press.

Gowdasiaei,F.(2005). An attribute-treatment interaction study: lexical-set versus semantically- unrelated vocabulary instruction. RELC journal , 36,341-361.

Gairns,R,\&Redman,S.(1986).working with words.Cambridge :Cambridge University Press.

Hashemi,M.R.,\&Gowdasiaei, F.(2005).An attribute-treatment interaction study :Lexical-set versus semanticallyunrelated vocabulary instruction.RELC Journal,36,341-361. 
Hippner-Page, T. (2000).Semantic clustering versus thematic clustering of English vocabulary words for second language instruction: Which method is more effective? Retrieved May 7, 2011, from

www.eric.ed.gov/ERICWebPortal/recordDetail?accno=ED445550.

Luke, S. D. (2006). The power of strategy instruction. Evidence for Education, 1 (1). Retrieved from nichcy.org/research/ee/learning-strategies.

Lynch,T.(1996).Communication in the language classroom.Oxford:Oxford university press.

Richards,J.c.\&Rodgers.T.S.(2001).Approaches and methods in language teaching. New York: Cambridge university press.

Seal,B.D.(1991).Vocabulary learning and teaching. In M.Celce-Murcia(Ed.),teaching English as a second or foreign language .( $2^{\text {nd }}$ ed.,pp.296-311).Boston: Heinle and Heinle.

Smith,Vicki L.(1983).Vocabulary building for university-bound ESL students. ERIC Document Reproduction Service No. ED 230037.

Tagashira, K., Kida, S., \& Hoshino, Y. (2010). Hot or gelid? The influence of L1 translation familiarity on the influence effects in foreign language vocabulary learning. System, 38, 412-421, doi: 10.1016/j.system.2010.03.015.

Thomas,b.J.(1986). Intermediate vocabulary book. England Longman group limited.

Tinkham,T.N.(1994).The effects of semantic and thematic clustering on the learning of second language vocabulary. unpublished doctoral dissertation. University of Illinois ,Urbana.

Tinkham, T. (1997). The effects of semantic and thematic clustering on the learning of second

language vocabulary. Second language research, 13(2), 138-163. 